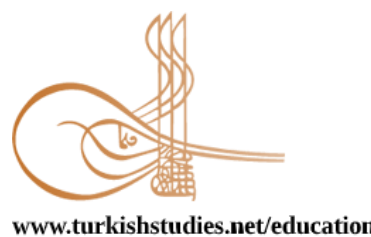

Turkish Studies - Educational Sciences

BALKAN
UNIVERSITY

Sponsored by IBU

Research Article / Araştırma Makalesi

\title{
Türkiye'de Ders İmecesi Çalışmalarındaki Eğilimler: Bir İçerik Analizi Çalışması
}

\author{
Lesson Study Studies Trends in Turkey: A Content Analysis Study
}

\author{
Hatice Aktuna* - Burçin Gökkurt Özdemir**
}

\begin{abstract}
In line with the approaches of learning that emphasize the social and contextual aspects of learning, there is a growing demand on collaborative professional development models. Lesson Study is a vocational development model that a group of teachers working with the cooperation of a target frame denominated "research class" in which they plan for classes, teach and evaluate. This study aims to examine postgraduate theses and articles focusing on lesson study to identify the trends in a comprehensive manner. The data of this research were collected by document analysis. For the purpose of this study, 14 master, 25 doctorate theses and 15 articles were indexed in TR completed in year between 2010-2019 were analyzed by using content analysis in Turkey. Frequency and percentace ratio involving data were presented by tables. The studies were classified within type of research, year of publication, approach of research, design of research, sample, subject and data analysis technique. The research results show that the doctorate thesis is more abundant than the master thesis as the thesis type and qualitative studies are predominant as research approach. It was observed that the participants of most of the examined studies were teachers. It was seen that case study is mostly preferred as a research design and using content analysis. As a review study, the present study was carried out in order to introduce lesson study construct to researchers and evaluate which aspects of lesson study were studied in Turkey and finally, make recommendations in light of the analysis of the studies for further research.
\end{abstract}

Structured Abstract: The teacher training implementations in Turkey carried out in the form of seminars fall short of the teachers' career development. Since the career development within the actual traditional methods cannot completely be promoted, it is needed for new approaches and models to go through with the progress. Those models begin to take part in the systems of many countries. One of those collusive development models carried out widespread around the world is the Lesson Study (LS) upgraded in Japan. Lesson study, which is an important component of Japanese education culture, has important effects on this country's education quality and success. Lesson study begins with finding and selecting materials relevant to the purpose of the class, and is then followed by refining the class design based on the actual needs of the students and tying all of this information together into a lesson plan. The significance of Lesson Study is that all of these processes are performed in collaboration with other teachers. Lesson study makes teaching approaches more practical and understandable to teachers through developing deeper understanding of content and student thinking. In this

\footnotetext{
* Yüksek Lisans Öğrencisi, Zonguldak Bülent Ecevit Üniversitesi, Fen Bilimleri Enstitüsü Master Student, Zonguldak Bülent Ecevit University, Institute of Sciences

Cite as/ Atıf: Aktuna, H. \& Gökkurt Özdemir, B. (2020). Türkiye'de ders imecesi çalışmalarındaki eğilimler: bir içerik analizi çalışması. Turkish Studies - Education, 15(4), 2629-2649. https://dx.doi.org/10.47423/TurkishStudies.43446

Received/Geliş: 16 May/Mayıs 2020

Accepted/Kabul: 27 August/Ağustos 2020

Copyright $\subset$ INTAC LTD, Turkey
Checked by plagiarism software

Published/Yayın: 30 August/Ağustos 2020 CC BY-NC 4.0 
manner, lesson study works effectively to connect theory and practice in Japan. Lesson Study is a vocational development model that a group of teachers working with the cooperation of a target frame denominated "research class" in which they plan for classes, teach and evaluate. One of the major facts about the model of lesson study is how the learner training progressed and to seek predictions for learners' thoughts. Lesson study helps cultivate a new attitude toward teaching, namely that teaching is not a one-way and didactic path, but a two-way integration of student ideas and content exploration meaningfully facilitated by teachers, an endeavor that can be extremely challenging. One of the important qualities of LS is that it places teachers' interests in the center of their learning process. In order for teachers to take full advantage of the opportunities of lesson study, they must be research-oriented and have inquisitive dispositions. The emphasis on student learning in the lesson study process continually reminds teachers how important it is for them to understand students' ideas and helps bring the visions of reform into their classrooms. The real classroom lives, past experiences and knowledge sharing feature in the process of effectuation of this estimate. The other major fact in lesson study is the sharing of knowledge and experience. The main purpose of lesson study is not planning the best class; to improve teachers' next teaching indeed. Teachers find the opportunity to observe their approach for the learners in the lesson study. They need the cooperative learning environments in which they come together with their colleagues constantly and more frequently for learning skills development and solving the encountered problems in their professional lives. Therefore, it is very important to adapt those new cooperative development models for the Turkish Education culture by analyzing them in detail. In this context, this study aims at examining postgraduate theses and articles focusing on lesson study to identify the trends in a comprehensive manner. The data of this research were collected by document analysis. For the purpose of this study, 14 master, 25 doctorate theses and 15 articles were indexed in Tr Indeks completed in year between 2010-2019 were analyzed by using content analysis in Turkey. In line with the content analysis, the classification was made according to the themes determined by the researchers. The studies were classified within type of research, year of publication, approach of research, design of research, sample, subject and data analysis technique. During the analysis process, a detailed search was carried out by the researcher with the keywords of "lesson study" and "ders imecesi" in the official site of National Council of Higher Education Thesis Center and indexed in Tr. The studies reached as a result of the review were transferred to the Microsoft Excel file. The studies reached in the second stage are classified according to seven themes. National Council of Higher Education Thesis Center Frequency and percentace ratio involving data were presented by tables. The research results show that the doctorate thesis is more abundant than the master thesis as the thesis type and qualitative studies are predominant as research approach. It was observed that the participants of most of the examined studies were teachers. It was seen that case study is mostly preferred as a research design and using content analysis. As a review study, the present study was carried out in order to introduce lesson study construct to researchers and evaluate which aspects of lesson study were studied in Turkey and finally, make recommendations in light of the analysis of the studies for further research.

Keywords: Mathematics Education, Research Trends, Lesson Study, Using Content Analysis, Teacher

Öz: Öğrenmede sosyal ve çevresel etkenleri vurgulayan yaklaşımlara bağlı olarak, işbirliğine dayalı mesleki gelişim modellerine yönelik ihtiyaçlar artmaktadır. Ders imecesi (Lesson Study) bir grup öğretmenin bir hedef çerçevesinde işbirliği içinde çalışarak araştırma dersi adı verilen dersler planladıkları, uyguladıkları ve değerlendirdikleri mesleki gelişim modelidir. Bu araştırma, ders imecesi ile ilgili olarak yazılan lisansüstü tezleri ve makaleleri kapsamlı bir şekilde inceleyerek eğilimlerini ortaya çıkarmak amacıyla yapılmıştır. Bu araştırmadan elde edilen veriler, doküman analizi yöntemi ile toplanmıştır. Çalışma için Türkiye'de 2010-2019 yılları arasında ders imecesi ile ilgili yapılan 14 yüksek lisans, 25 doktora tezi ve 15 TR-Dizin indeksli makale içerik analizi kullanılarak incelenmiştir. Araştırmadan elde edilen veriler frekans ve yüzde oranlarına göre yorumlanarak tablolarla sunulmuştur. Tezler, araştırma türü, yayımlanma yılı, araştırma yaklaşımı, araştırma deseni, örneklem, konu ve veri analizi teknikleri kapsamında sınıflandırılmıştır. Araştırma sonuçları, tez türlerine göre doktora tezlerinin yüksek lisans tezlerine göre daha fazla olduğunu, yaklaşım olarak nitel çalışmaların ağırlıkta olduğunu göstermektedir. İncelenen araştırmaların çoğunun katılımcılarının öğretmenler olduğu gözlemlenmiştir. Araştırma deseni olarak çoğunlukla durum çalışması tercih edildiği ve içerik analizinin kullanıldığı görülmektedir. Bir alan taraması olan bu çalışma, ders imecesi alanında araştırma yapmak isteyen araştırmacılara hem ders imecesini tanıtmak hem de Türkiye'de bu alanda hangi noktaların çalışıldığını ve eksikliklerin neler olduğunu göstermek amacıyla gerçekleştirilmiştir.

Turkish Studies - Education, 15(4) 
Anahtar Kelimeler: Matematik Eğitimi, Araştırma Eğilimleri, Ders İmecesi, İçerik Analizi, Öğretmen

\section{Giriş}

Mesleki gelişim programları, öğretmenlerin farklı bir bakış açısına sahip olması ve bu bakış açısı ile farklı stratejiler geliştirmesini amaçlamaktadır (Borko, 2004). Mesleki gelişim programlarında kullanılan modellerin başında "lesson study"' gelmektedir (Isoda, 2007). Lesson study, iş birliği çalışmasına dayalı, öğretmenlerin mesleki gelişimlerinde kullanılan, kökeni Japonya'ya dayanan bir öğretmen yetiştirme, geliştirme yaklaşımıdır. Lesson study, farklı ülkelerde çeşitli şekilde adlandırılmaktır. Örnek olarak, Singapur'da Eylem Araştırması, Çin'de Eylem Eğitimi olarak adlandırılmıştır (Sato, 2006). Ders araştırması anlamına gelen lesson study, öğretmenlerin ya da öğretmen adaylarının bir araya gelerek grupça etkili ders planı hazırlamasını, dersin yürütülmesini ve değerlendirilmesini içermektedir. Dolayısıyla bu çağrışımların bir araya gelmesi ile yardımlaşma ön planda olduğu için bu model daha çok "'Ders İmecesi'" olarak adlandırılmaktadır (Bütün, 2012).

Ders imecesinin dünya genelindeki kültürel farkl1lıklardan dolayı, hizmet içi ve öncesi öğretmen eğitimlerinde değişikliklik göstermektedir (Murata, 2011). Ders imecesi ile öğretmenler, öğrenci düşünme ve öğrenme süreçlerine, öğretim materyallerine, öğretim programına, öğretim süreçlerine ve eğitim amaçlarına ilişkin farklı anlayışlar geliştirmektedirler (Verhoef, vd., 2015). Ders imecesi, Japonya'da yaşayan öğretmenlerin mesleki açıdan kendi çalışmalarını değerlendirmek için kullandıkları bir mesleki gelişim sürecidir. Ders imecesinin amaçları; öğrenci öğrenmesini ön planda tutarak, işbirliği ile ders planı hazırlanması, hazırlanan ders planın uygulanması, değerlendirilmesi ve geliştirilmesidir. Bu model ile öğretmenlerin öğrenmeye farklı bakış açılarıyla bakması sağlanmaktadır (Stigler \& Hiebert, 1999). Murata (2011), ders imecesine katılan öğretmenlerin öğretim şekillerinin daha gelişmiş olduğuna ve öğrenci düşüncelerine karşı daha farklı bir anlayışa sahip olduklarını vurgulamıştır. Stigler ve Hiebert (2016) ders imecesinin en önemli ve öncelikli amacının öğretmenlerin sonraki öğretimlerini geliştirmek olduğunu ifade etmişlerdir. Ders imecesinde yapılan tüm etkinlik ve uygulamaların merkezinde öğrenciler yer almaktadır (Takahashi \& Yoshida, 2004).

Ders imecesi modeli, ders imecesi grubu içinde yer alan bireylerin bir araya gelerek bir konuya yönelik yürüttükleri planlama, öğretim ve tartışma aşamalarını kapsayan bir döngüden oluşmaktadır (Baki, 2012). Fernandez ve Yoshida (2004) ders imecesinin; model planlama, öğretim/gözlemleme, tartı̧̧ma, revize etme, yeniden öğretim/gözlemleme ve tartışma olmak üzere altı aşamadan oluştuğunu ifade etmiştir. Öğretmen adaylarının ve öğretmenlerin ders imecesi modelinde ilk yaptıkları çalışma hedefledikleri kazanımlara yönelik ders planı hazırlamalarıdır. Bu süreçte kazanımlarla ilgili soru, etkinlik, çalışma yaprağı vb. hazırlayarak, sorular üzerinde tartışmakta, öğrencilerin verebilecekleri cevaplara yapabilecekleri geri dönütleri düşünmekte, öğrencilerin düşüncelerini önceden tahmin etmeye ve öğrencilerin bakış açısıyla dersin içeriğini değerlendirmektedirler. Öğretmen adaylarının ve öğretmenlerin düşüncelerini paylaşmaları ise bu noktada kazanım ile ilgili farklı bakış açılarını ortaya koymakta ve öğrencilerin ne kadar farklı düşünebileceğini göstermektedir (Lewis, Friedkin, Baker, \& Perry, 2011). Planlama aşamasından sonra planlama ile ilgili ön değerlendirme raporu hazırlanarak, öğretmen adaylarının ve öğretmenlerin katılımı ile bir uygulama dersi yapılmaktadır. Bu derste grup içinden bir öğretmen ya da öğretmen adayı hazırladıkları plana uygun bir biçimde dersi anlatırken diğer grup üyeleri dersi gözlemlemektedir. Ders bitiminde ders ile ilgili bir rapor hazırlanmaktadır. Hazırlanan raporda hedeflere ne kadar ulaşıldığ 1 , dersin nasıl geçtiği ve dersin tekrarında nelerin değiştirebileceği ve düzeltilebileceği yer almaktadır (Özbek, 2019). Ders planını öğrencilerin öğrenme düzeyine ve düşünme şekillerine göre değiştirmek oldukça önemlidir (Yoshida, 2005). Sinıfta ders anlatımı sırasında gözlemciler dersi anlatan kişinin davranışlarına odaklanmak yerine öğrenci tepkilerine odaklanarak gözlem yaparlar. Ayrıca gözlemciler, hedef davranışlara yönelik veri toplamaya 
çalışırlar (Armstrong, 2011). Tartışma aşamasında odaklanılan şey öğrenci anlamaları-öğrenmeleri, dersin nasıl daha iyi bir şekilde geliştirebileceğiyle ilgilidir (Doig \& Groves, 2011; Takahashi \& Yoshida, 2004). Çoğunlukla sınıfta gözlem yapılırken dışardan bir katılımeı derse katılmaktadır. Farklı gözlemci katılmasının sebebi farklı imece grubu çalışmalardan paylaşım yapmak ve farklı bir bakış açısı sağlamaktır (Fernandez, Yoshida, Chokshi, \& Cannon, 2001). Bu gözlemciler, gözlem yaptıkları ve geri dönüt verdikleri için anahtar bir role sahiptirler (Eraslan, 2008). Ders imecesi grubunun içinde bulunan uzman, süreci tek başına yönetmez, sadece gruba rehberlik eder (Erbilgin, 2013). Ders imecesinin Japonya'da popülerliğini kaybetmemesinin sebepleri olarak meslektaşlar arasında işbirliğini sağlaması, öğrenme ve öğretme konularına farklı bir bakış açısı getirmesi, fikir alışverişinin fazla olması gösterilmektedir (Takahashi \& Yoshida, 2004). Bozkurt ve YetkinÖzdemir (2018), Türkiye'de seminer şeklinde yürütülmekte olan öğretmen eğitimi uygulamalarının, öğretmenlerin mesleki gelişimlerinde yetersiz kaldığını vurgulamaktadır. Benzer şekilde Küçükahmet (1993), öğretmenlerin mesleki gelişimlerinin var olan geleneksel yöntemler kapsamında tam olarak desteklenemediğini ve bunu gerçekleştirmede yeni yaklaşımlara, modellere ihtiyaç duyulduğunu ifade etmektedir. Japonya'da geliştirilmiş olan ve birçok ülkede yaygın olarak yürütülen işbirliğine dayalı mesleki gelişim modellerinden biri olan ders imecesi modeli, (Bozkurt \& Yetkin-Özdemir, 2018), farklı seviyedeki öğretmenlerin bilgi alışverişi için bir firsattır (Chokshi \& Fernandez, 2004). Ders imecesi öğretmenlerin ve öğretmen adaylarının mesleki gelişimini desteklemektedir (Baki, 2012). Öğretmenler dersi imecesi modelinde planlama yaparken, öğrencilerin olası cevaplarını tahmin etmeye çalışırlar. Planlama sırasında öğretmenler, içerik bilgilerinin geliştirilmesine yardımcı olabilecek öğretim materyallerini inceleme firsatı bulurlar. Ders boyunca öğretmenler, öğrencinin görüşlerine katılırlar ve farklı öğrenci yaklaşımları hakkında not alırlar. Bu bakımdan ders imecesi öğretmenlerin stratejilerini etkilemektedir (Gómez vd., 2019).

Ders imecesi üzerine yürütülen çalışmalar incelendiğinde, birçok araştırmacının bu konuyu çalıştığ1 görülmektedir (Aktürk, 2019; Baki \& Arslan, 2015; Bayram \& Bıkmaz, 2019; Boran \& Tarım, 2016; Cumhur, 2016; Güner \& Akyüz, 2017; Jhang, 2020; Karakuş, 2019; Kandemir, 2018; Kaya, 2018; Özaltun Çelik \& Bukova Güzel, 2016; Özbek, 2019; Yılmaz, 2019; Yurdakul, 2019). Alanyazın incelendiğinde ders imecesi üzerine hazırlanan çalışmaların uygulamaya dönük çalışmalar olduğu, genellikle öğretmenler ya da öğretmen adayları ile yürütüldüğü dikkat çekmektedir. Mesleki gelişim modeli olarak birçok ülkede kullanılan (Gökkurt-Özdemir, 2020) bu modelin öneminden hareketle, Türkiye'de ders imecesi modeli üzerine alan taraması niteliği taşıyan çalışmaya rastlanamamıştır. Bu doğrultuda bu araştırma, alan taraması niteliğinde olup, ders imecesinin Türkiye'de ne düzeyde çalışıldığını ortaya koyacaktır. Böylelikle bu araştırmadan elde edilen bulguların ders imecesi üzerine hangi çalışmalara ihtiyaç duyulduğuna 1 şık tutacağ 1 düşünülmektedir.

\section{Çalışmanın Amacı}

Bu araştırmanın amacı, 2010 yılından 2019 yılına kadar Türkiye'de Ulusal tez merkezinde ders imecesi üzerine yapılan doktora-yüksek lisans tezlerini ve TR Dizinde taranan makaleleri farklı temalara göre incelemektir. Bu amaç kapsamında araştırma sorusu "Ders imecesi üzerine incelenen çalışmaların sonuçlarına göre dağılımı nasıldır?” şeklindedir. Bu araştırma sorusu doğrultusunda alt problemler şu şekildedir:

Ders imecesi üzerine incelenen çalışmaların;

1. Araştırma türlerine göre dağılımı nasıldır?

2. Yayın yılına göre dağılımı nasıldır?

3. Araştırma yaklaşımına göre dağ 11 ımı nasıldır?

4. Örneklem çeşitlerine göre dağılımı nasıldır?

5. Araştırma desenine göre dağ $11 ı \mathrm{~m} ı$ nasıldır?

6. Konuların öğrenme alanlarına göre dağ 11 ımı nasıldır?

7. Kullanılan analiz tekniklerine göre dağılımı nasıldır? 


\section{Yöntem}

$\mathrm{Bu}$ araştırmanın verileri nitel araştırma yöntemlerinden doküman incelemesi ile toplanmıştır. Doküman incelemesi ya da doküman analizi, araştırılması hedeflenen olgu veya olgular hakkında bilgi içeren yazılı materyallerin analizini kapsar (Yıldırım \& Şimşek, 2013:217-219). Bu araştırmanın amacı doğrultusunda ölçüt olarak "ders imecesi" ya da "lesson study "kelimeleri anahtar kelimeler olarak belirlenerek ilgili araştırmalar içerik analizine dâhil edilmiştir. Araştırma kapsamına alınan çalışmaları belirlemek amacıyla Yükseköğretim Kurulu Başkanlığı YÖK- Ulusal Tez Merkezi bünyesinde gelişmiş tarama yapılmıştır. Tarama çalışması yapılırken Ulakbim/TR DİZIN indeksli makaleler çalıșmaya dâhil edilmiștir. Tarama çalıșması 2010-2019 yıllarını kapsayacak șekilde yapılmıştır. Tarama sonucunda 25 doktora tezi, 14 yüksek lisans tezi ve 15 Ulakbim/TR DİZİN indeksli makale olmak üzere toplam 54 araştırmaya ulaşılmıştır (Ek-1).

\section{Verilerin Analizi}

Araştırmalardan elde edilen verilerin analizinde içerik analizi kullanılmıştır. İçerik analizi kısaca birbirine benzeyen verileri belli kavramlar ve temalar çerçevesinde bir araya getirmek ve bunları anlaşı1ır bir biçimde düzenleyerek yorumlamaktır (Yıldırım \& Şimşek, 2013:259). İçerik analizi doğrultusunda araştırmacılar tarafından belirlenen temalara göre sınıflandırılma yapılmıştır. Sınıflandırılma; araştırma türü, yayın yıll, araştırma yaklaşımı, örneklem, araştırma deseni, konu ve analiz teknikleri temaları olmak üzere yedi tema şeklinde belirlenmiştir. Analiz sürecinde araştırmacı tarafından ilk aşamada Yükseköğretim Kurulu Başkanlığ 1 YÖK Ulusal Tez Merkezi ve TR Dizin bünyesinde lesson study ve ders imecesi anahtar kelimeleri ile detaylı arama yapılmıştır. Tarama sonucunda ulaşılan çalışmalar Microsoft Excel dosyasına aktarılmıștır. İkinci aşamada ulaşılan çalışmalar belirlenen yedi tema doğrultusunda sınıflandırılmıştır. Araştırmanın güvenirliği için araştırmacı tarafından oluş̧turulan sınıflandırma analizi ders imecesi alanında uzman bir öğretim üyesinin görüşlerine sunulmuştur. Uzman görüşleri kapsamında, bazı çalışmaların analizi detaylandırılmıştır. Örneğin tarama sonucunda nitel araştırma yaklaşımının benimsendiği bir makale çalışmasında araştırmanın yöntemi açık bir şekilde ifade edilmemiştir. Uzman görüşleri doğrultusunda araştırmanın yöntemi durum çalışması olarak düzenlenmiştir.

\section{Bulgular}

Bu bölümde "ders imecesi'" ya da "lesson study" anahtar kelimelerini içeren 54 çalışmaya ait bulgular, araştırmanın türü, yayın yılı, araştırmanın yaklaşımı, örneklem çeşitleri, deseni, öğrenme alanı ve analiz teknikleri olmak üzere yedi alt başlık halinde sunulmuştur. 


\section{Araştırma Türlerine İlişkin Bulgular}

Tablo 1: Araştırma Türlerine Göre Frekans ve Yüzde Değerleri

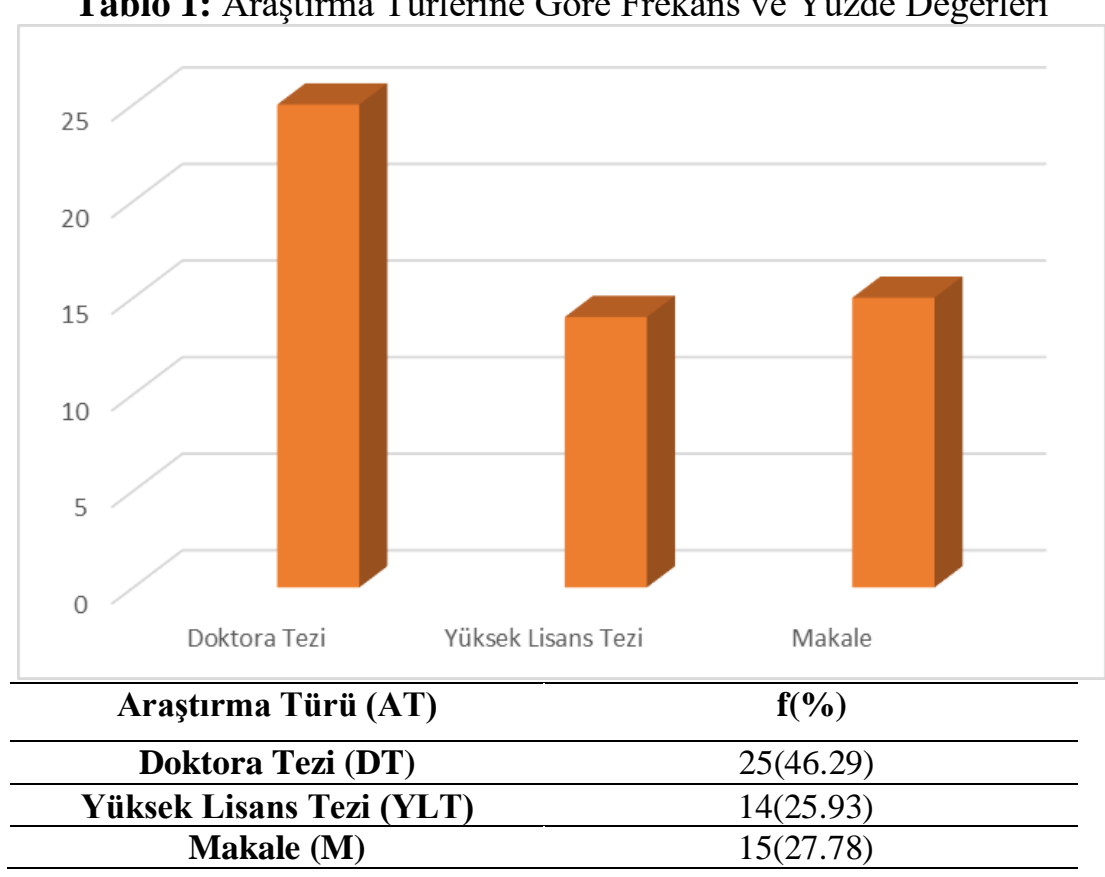

Araştırma türlerine göre dağılım incelendiğinde doktora tezinin; yüksek lisans tezine ve makaleye oranla daha fazla olduğu görülmektedir. Tez ve makalelerin dağılım şekli olarak 25 $(\% 46,29)$ doktora tezine, $14(\% 25,93)$ yüksek lisans tezi ve $15(\% 27,78)$ makaleye rastlanmıştır.

\section{Araştırmaların Yayınlanma Yılına İliş̧kin Bulgular}

Tablo 2: Araştırmaların Yayınlandığı Yıla Göre Frekans ve Yüzde Değerleri

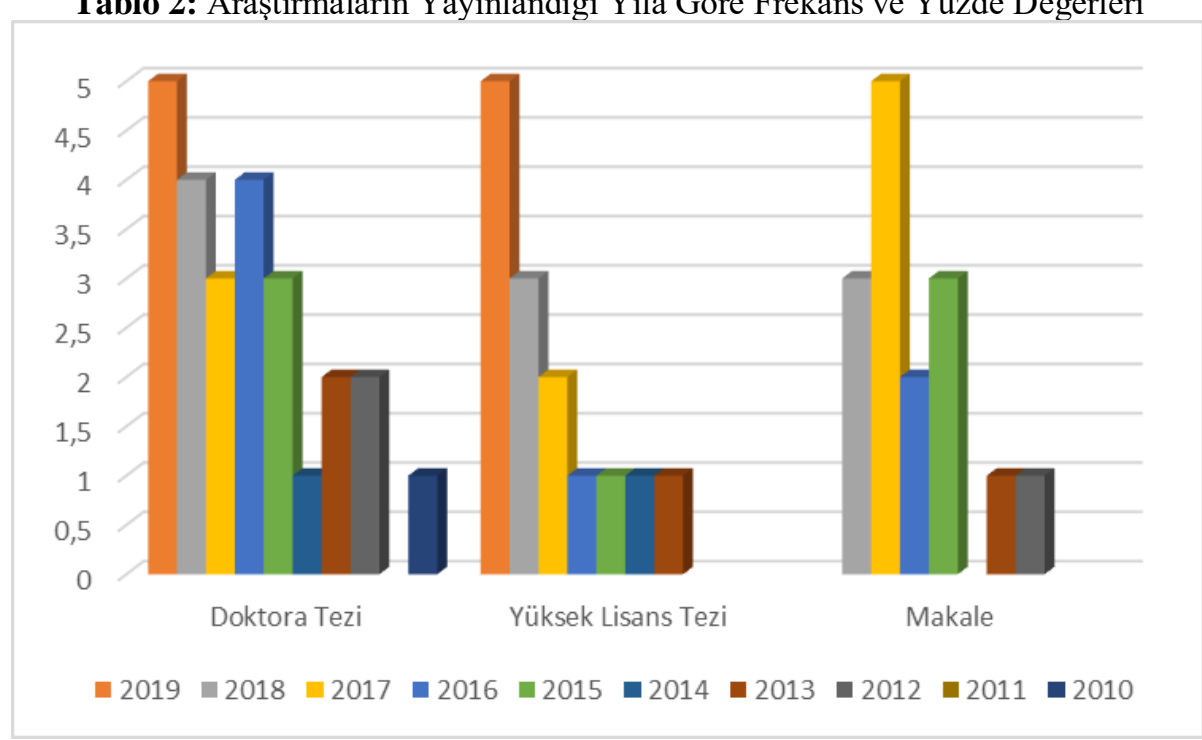

\begin{tabular}{ccccccccccc}
\hline Yll & $\mathbf{2 0 1 9}$ & $\mathbf{2 0 1 8}$ & $\mathbf{2 0 1 7}$ & $\mathbf{2 0 1 6}$ & $\mathbf{2 0 1 5}$ & $\mathbf{2 0 1 4}$ & $\mathbf{2 0 1 3}$ & $\mathbf{2 0 1 2}$ & $\mathbf{2 0 1 1}$ & $\mathbf{2 0 1 0}$ \\
\hline AT & & & & & $\mathbf{f}(\boldsymbol{\%})$ & & & & \\
\hline DT & $5(9.3)$ & $4(7.4)$ & $3(5.6)$ & $4(7.4)$ & $3(5.6)$ & $1(1.83)$ & $2(3.7)$ & $2(3.7)$ & $1(1.83)$ \\
\hline YLT & $5(9.3)$ & $3(5.6)$ & $2(3.7)$ & $1(1.83)$ & $1(1.83)$ & $1(1.83)$ & $1(1.83)$ & & \\
\hline M & & $3(5.6)$ & $5(9.3)$ & $2(3.7)$ & $3(5.6)$ & & $1(1.83)$ & $1(1.83)$ & & \\
\hline Top & $\mathbf{1 0}(\mathbf{1 8 . 6})$ & $\mathbf{1 0}(\mathbf{1 8 . 6})$ & $\mathbf{1 0}(\mathbf{1 8 . 6})$ & $\mathbf{7 ( 1 2 . 9 )}$ & $\mathbf{7 ( 1 2 . 9 )}$ & $\mathbf{2 ( 3 . 7 )}$ & $\mathbf{4 ( 7 . 4 )}$ & $\mathbf{3 ( 5 . 6 )}$ & $\mathbf{1 ( 1 . 8 3 )}$ \\
\hline
\end{tabular}


Araştırmanın yıllara göre dağılımı incelendiğinde 2019, 2018, 2017 yıllarında 10'ar çalışma, 2016 ve 2015 yıllarında 7 çalışma, geriye kalan yıllarda çok az sayıda çalışma yapılmıştır. 2011 yılında yapılan bir çalışmaya rastlanamamıştır.

\section{Araştırma Yaklaşımına İlişkin Bulgular}

Tablo 3: Araştırma Yaklaşımına Göre Frekans ve Yüzde Değerleri

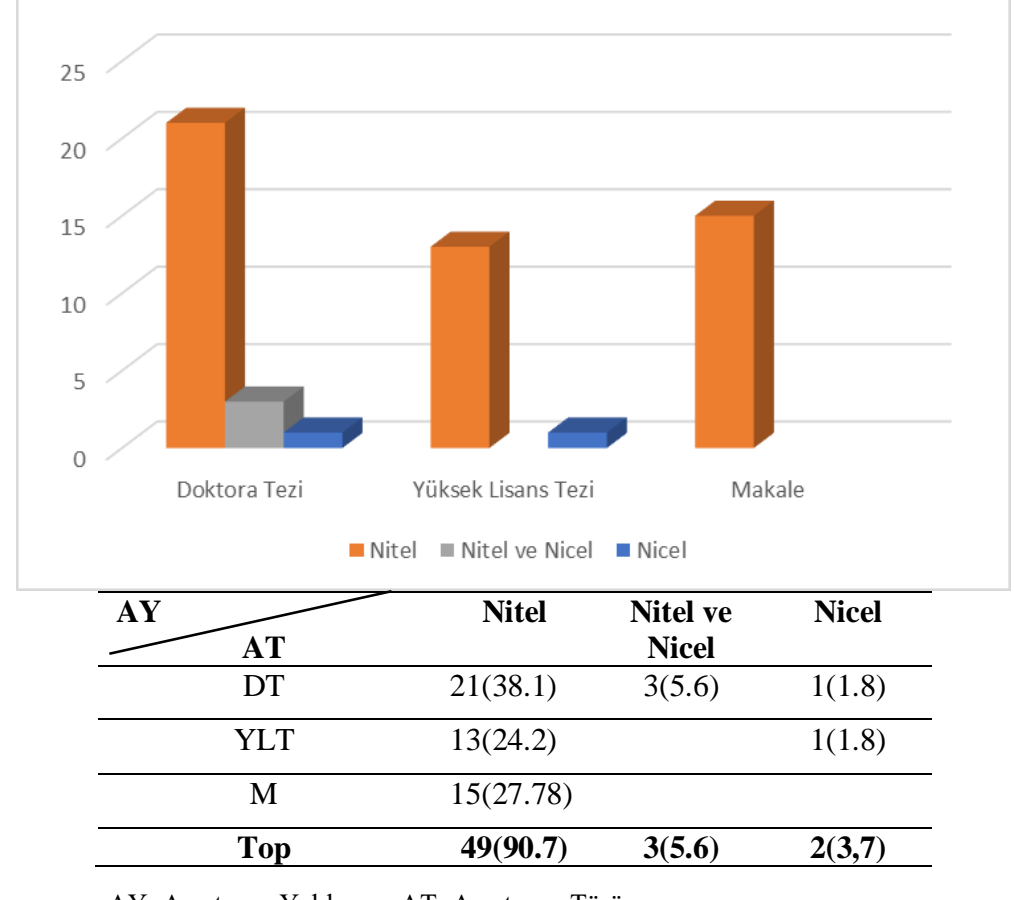

AY: Araştırma Yaklaşımı AT: Araştırma Türü

Araştırma yaklaşımına göre incelendiğinde, ders imecesi üzerine yapılan tüm çalışmaların büyük bir çoğunluğu (\%90.7) nitel araştırma yaklaşımına dayalı yürütülmüş̧ür. Bu çalışmaların arasında da en çok doktora tezi yer almaktadır. Ders imecesi üzerine nicel yaklaşımın kullanıldığı çalışmaların sayısı oldukça sınırlı olup, bu çalışmalar da sadece doktora tezleridir. 


\section{Araştırmanın Yürütüldüğü Örnekleme İlişkin Bulgular}

Tablo 4: Araştırmanın Yürütüldüğü Örnekleme Göre Frekans ve Yüzde Değerleri

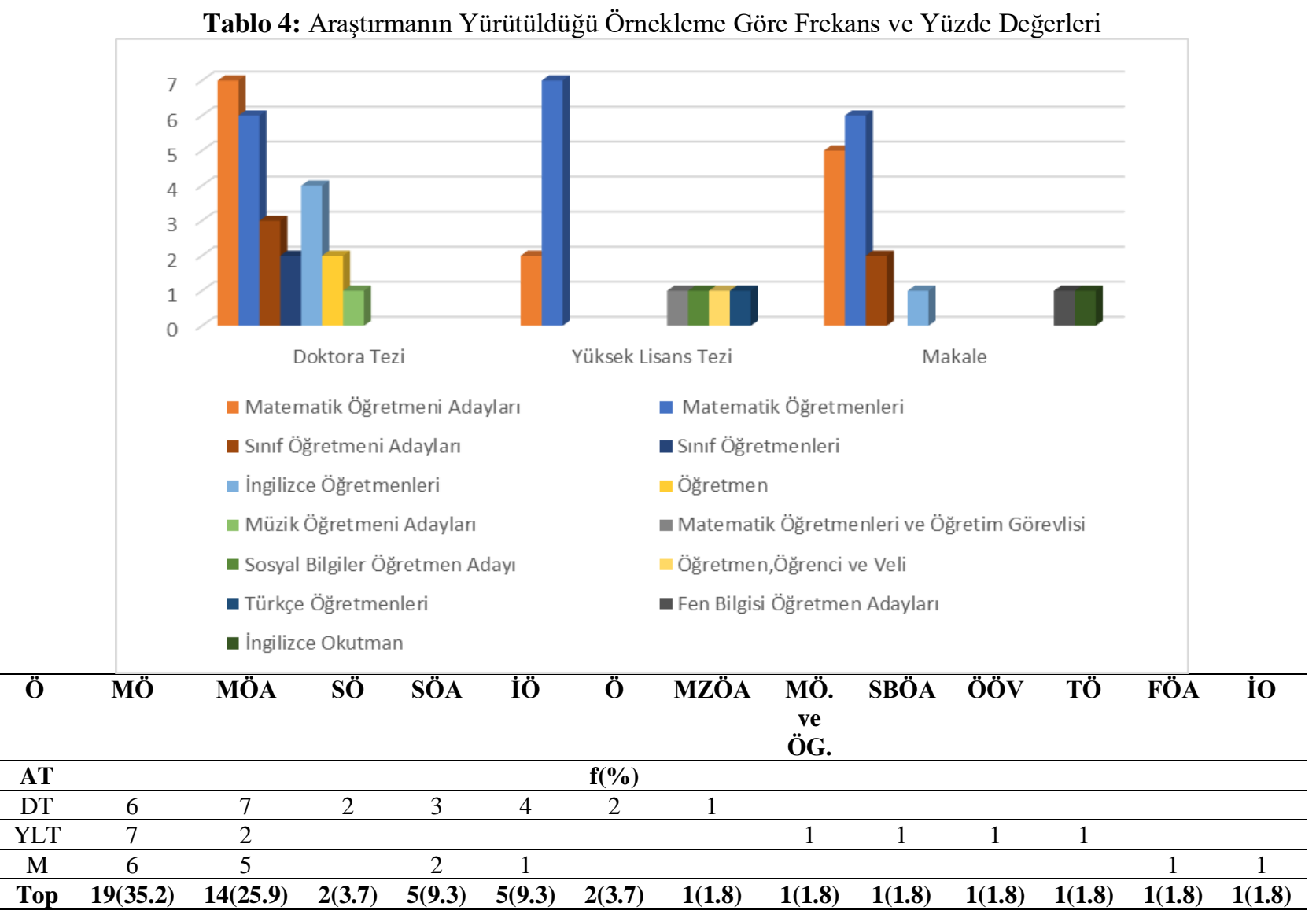

Ö: Örneklem, MÖ: Matematik öğretmeni, MÖA: Matematik öğretmeni adayı, SÖ: Sınıf öğretmeni, SÖA: Sınıf öğretmeni adayı, İÖ: İngilizce öğretmeni, MZÖA: Müzik öğretmeni adayı, Ö: Öğretmen, ÖG: Öğretim görevisi, SBÖA: Sosyal bilgiler öğretmeni adayı ÖÖ V: Öğretmen, öğrenci, veli, TÖ: Türkçe öğretmeni, FÖA: Fen Bilgisi öğretmeni adayı İO: İngilizce okutman,

Tablo 4 incelendiğinde öğretmenler ile yapılan çalışmaların öğretmen adayları ile yapılan çalışmalardan daha fazla olduğu görülmektedir. Disiplin olarak incelendiğinde ise çalışmalarda daha çok matematik öğretmeni ve matematik öğretmeni adayı ile çalışıldığ1 görülmüştür. Fen bilgisi öğretmenleri ile yapılan çalışılmaya rastlanılmadığı dikkat çekmektedir. 


\section{Araştırma Desenine İlişkin Bulgular}

Tablo 5: Araştırma Desenine Göre Frekans ve Yüzde Değerleri

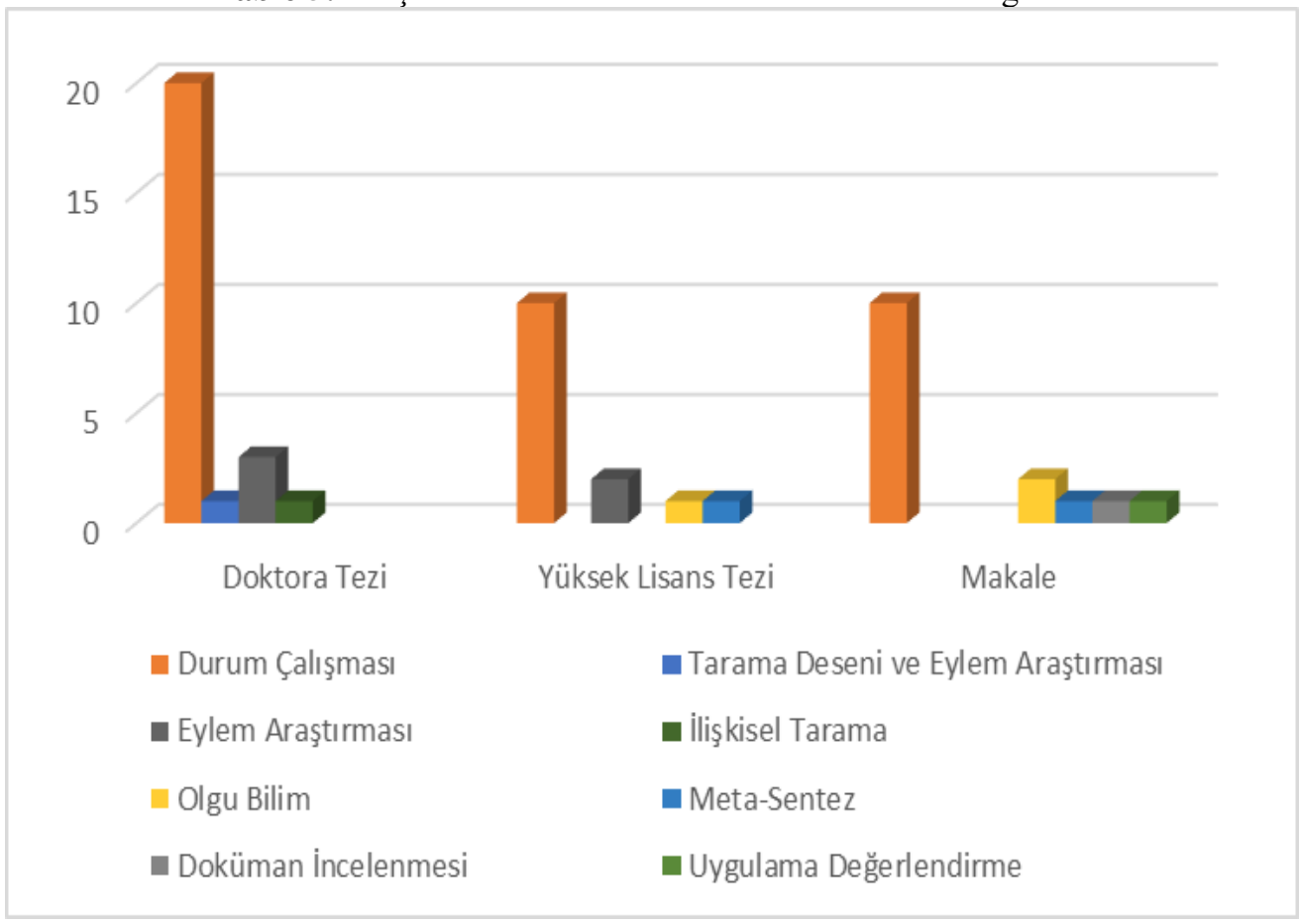

\begin{tabular}{lllllllll}
\hline Desen & $\begin{array}{l}\text { Durum } \\
\text { Çalışması }\end{array}$ & $\begin{array}{l}\text { Tarama } \\
\text { Deseni } \\
\text { Eylem } \\
\text { Araştırması }\end{array}$ & $\begin{array}{l}\text { Eylem } \\
\text { Araştırması }\end{array}$ & $\begin{array}{l}\text { İlişkisel } \\
\text { Tarama }\end{array}$ & $\begin{array}{l}\text { Olgu } \\
\text { Bilim }\end{array}$ & $\begin{array}{l}\text { Meta- } \\
\text { Sentez }\end{array}$ & $\begin{array}{l}\text { Doküman } \\
\text { Incelenmesi }\end{array}$ & $\begin{array}{l}\text { Uygulama } \\
\text { Değerlendir- } \\
\text { me }\end{array}$ \\
\hline AT & & & $\mathbf{f}(\%)$ \\
\hline DT & $20(37.1)$ & $1(1.8)$ & $3(5.6)$ & $1(1.8)$ & & & & \\
\hline YLT & $10(18.5)$ & & $2(3.7)$ & & $1(1.8)$ & $1(1.8)$ & & $1(1.8)$ \\
\hline M & $10(18.5)$ & & & & $2(3.7)$ & $1(1.8)$ & $1(1.8)$ & $\mathbf{1 ( 1 . 8 )}$ \\
\hline Top & $\mathbf{4 0}(\mathbf{7 4 , 1 )}$ & $\mathbf{1 ( 1 . 8 )}$ & $\mathbf{5 ( 9 . 3 )}$ & $\mathbf{1 ( 1 . 8 )}$ & $\mathbf{3 ( 5 . 6 )}$ & $\mathbf{2 ( 3 . 7 )}$ & $\mathbf{1 ( 1 . 8 )}$ & \\
\hline
\end{tabular}

Araştırma desenine ait bulgular incelendiğinde, tüm çalışmalara göre doktora tezlerinden 20 (\%37.1) durum çalışması, 1 (\%1.8) tarama deseni ve eylem araştırması, 3 (\%5.6) eylem araştırması ve 1 (\%1.8) ilişkisel tarama deseni olduğu görülmektedir. Yüksek lisans tezine ait bulgular incelendiğinde, 10 (\%18.5) durum çalışması, 2 (\%3.7) eylem araştırması, 1 (\%1.8) olgu bilim, 1 (\%1.8) meta-sentez çalışması olduğu görülmektedir.

Makale çalışmaları incelendiğinde ise 10 (\%18.5) durum çalışması, 2 (\%3.7) olgu bilim, 1 (\%1.8) meta-sentez, $1(\% 1.8)$ doküman incelemesi ve $1(\% 1.8)$ uygulama değerlendirme olduğu dikkat çekmektedir. Çalışmalar bütün olarak değerlendirildiğinde tercih edilen desenin en çok 40 (\%74.1) durum çalışması olduğu görülmektedir. 


\section{Çalışılan Konulara İlişskin Bulgular}

Tablo 6: Çalışılan Konulara Göre Frekans ve Yüzde Değerleri

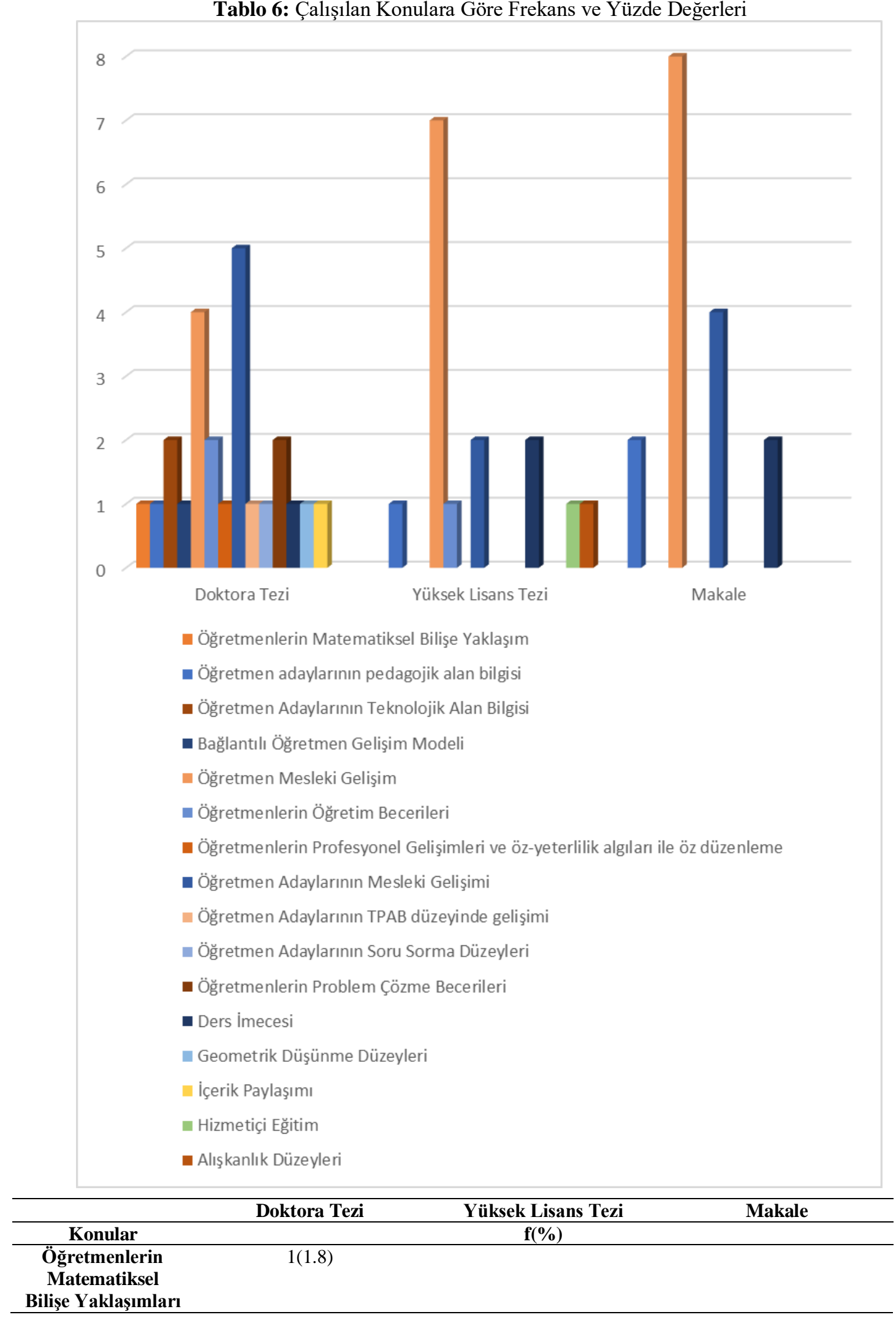

Turkish Studies - Education, 15(4) 


\begin{tabular}{|c|c|c|c|}
\hline $\begin{array}{c}\text { Öğretmen } \\
\text { Adaylarının } \\
\text { Pedagojik Alan } \\
\text { Bilgisi }\end{array}$ & $1(1.8)$ & $1(1.8)$ & $2(3.7)$ \\
\hline $\begin{array}{c}\text { Öğretmen } \\
\text { Adaylarının } \\
\text { Teknolojik Alan } \\
\text { Bilgisi } \\
\end{array}$ & $2(3.7)$ & & \\
\hline $\begin{array}{c}\text { Bağlantılı } \\
\text { Öğretmen Gelişim } \\
\text { Modeli }\end{array}$ & $1(1.8)$ & & \\
\hline $\begin{array}{c}\text { Öğretmen Mesleki } \\
\text { Gelişim }\end{array}$ & $4(7.4)$ & $7(12.9)$ & $8(14.8)$ \\
\hline $\begin{array}{c}\text { Öğretmenlerin } \\
\text { Öğretim Becerileri }\end{array}$ & $2(3.7)$ & $1(1.8)$ & \\
\hline $\begin{array}{l}\text { Öğretmenlerin } \\
\text { Profesyonel } \\
\text { Gelişimleri ve öz- } \\
\text { yeterlilik algıları } \\
\text { ile öz düzenleme } \\
\end{array}$ & $1(1.8)$ & & \\
\hline $\begin{array}{c}\text { Öğretmen } \\
\text { Adaylarının } \\
\text { Mesleki Gelişimi }\end{array}$ & $5(9.3)$ & $2(3.7)$ & $4(7.4)$ \\
\hline $\begin{array}{c}\text { Öğretmen } \\
\text { Adaylarının TPAB } \\
\text { düzeyinde gelişimi }\end{array}$ & $1(1.8)$ & & \\
\hline $\begin{array}{c}\text { Öğretmen } \\
\text { Adaylarının Soru } \\
\text { Sorma Düzeyleri }\end{array}$ & $1(1.8)$ & & \\
\hline $\begin{array}{c}\text { Öğretmenlerin } \\
\text { Problem Çözme } \\
\text { Becerileri }\end{array}$ & $2(3.7)$ & & \\
\hline Ders İmecesi & $1(1.8)$ & $2(3.7)$ & $2(3.7)$ \\
\hline $\begin{array}{l}\text { Geometrik } \\
\text { Düşünme } \\
\text { Düzeyleri }\end{array}$ & $1(1.8)$ & & \\
\hline İçerik Paylaşımı & $1(1.8)$ & & \\
\hline Hizmetiçi Eğitim & & $1(1.8)$ & \\
\hline $\begin{array}{l}\text { Alışkanlık } \\
\text { Düzeyleri }\end{array}$ & & $1(1.8)$ & \\
\hline Top & $25(46.29)$ & $14(25.93)$ & 15(27.78) \\
\hline
\end{tabular}

Yapılan çalışmaların konusu incelendiğinde tüm çalışmalara göre doktora tezlerinden 5'inin (\%20) öğretmen adaylarının mesleki gelişimi üzerine olduğu görülmektedir. Yüksek lisans tezlerinin ise 7'sinin (\%12.9) öğretmen mesleki gelişimi üzerine olduğu görülmektedir. Makalelerin 8'i (\%14.8) öğretmen mesleki gelişim üzerinedir. Çalışmalar genel olarak değerlendirildiğinde, öğretmen mesleki gelişimi üzerine yürütülen çalışmaların yüzdesi $(\% 35,18)$ diğerlerine kıyasla fazladır. 
Araştırmada Kullanılan Analiz Türlerine Ait Bulgular

Tablo 7: Analiz Türlerine Göre Frekans ve Yüzde Değerleri

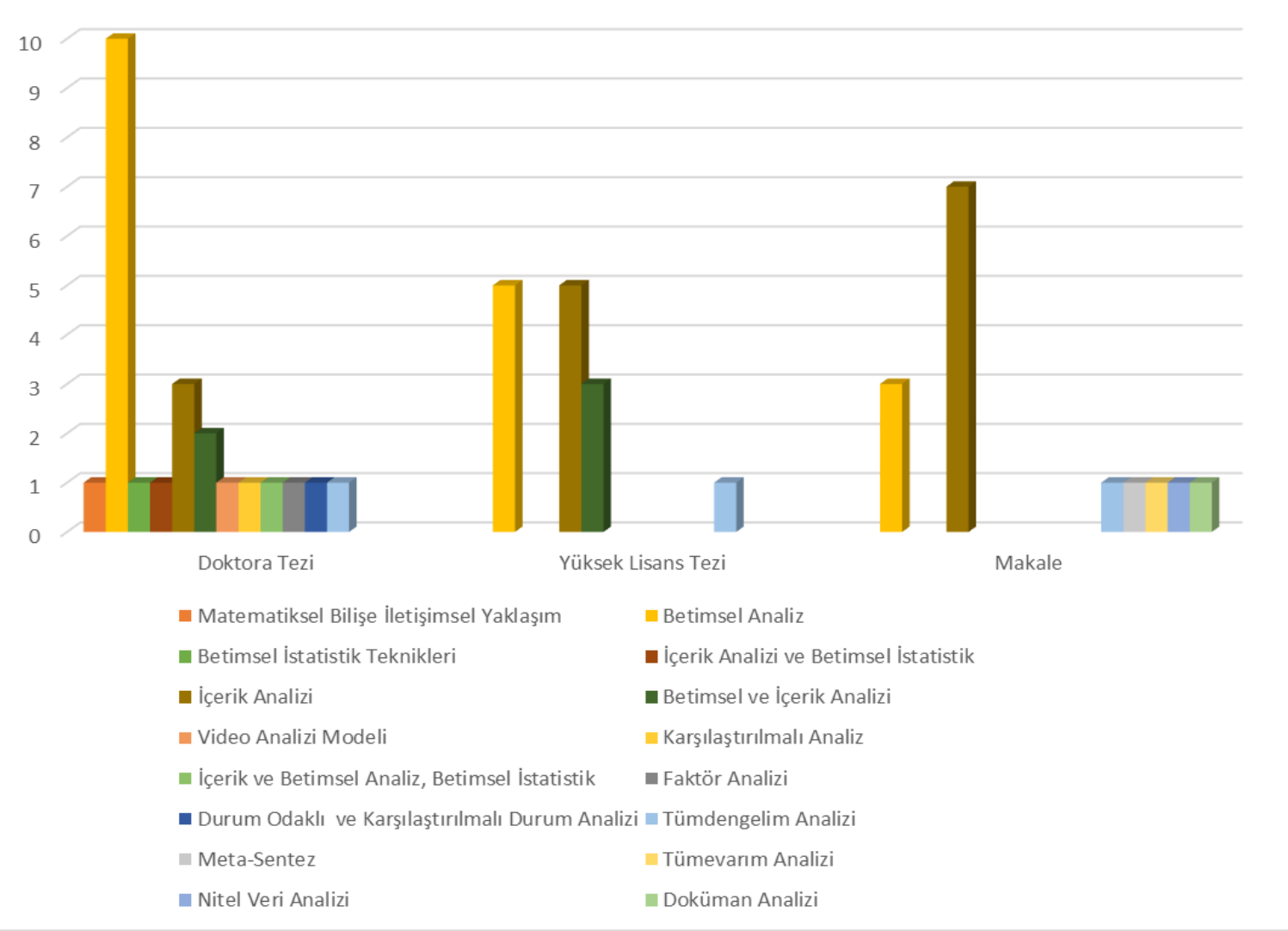

\begin{tabular}{|c|c|c|c|}
\hline & Doktora Tezi & Yüksek Lisans Tezi & Makale \\
\hline Analiz Türü & & $\mathbf{f}(\%)$ & \\
\hline Matematiksel & $1(1.8)$ & & \\
\hline $\begin{array}{c}\text { Bilişe İletişimsel } \\
\text { Yaklaşım }\end{array}$ & & & \\
\hline Betimsel Analiz & 10(18.5) & $5(9.3)$ & $3(5.6)$ \\
\hline $\begin{array}{c}\text { Betimsel İstatistik } \\
\text { Teknikleri }\end{array}$ & $1(1.8)$ & & \\
\hline $\begin{array}{l}\text { İçerik Analizi ve } \\
\text { Betimsel İstatistik }\end{array}$ & $1(1.8)$ & & \\
\hline İçerik Analizi & $3(5.6)$ & $5(9.3)$ & $7(12.9)$ \\
\hline $\begin{array}{c}\text { Betimsel ve İçerik } \\
\text { Analizi }\end{array}$ & $2(3.7)$ & $3(5.6)$ & \\
\hline $\begin{array}{c}\text { Video Analizi } \\
\text { Modeli }\end{array}$ & $1(1.8)$ & & \\
\hline $\begin{array}{c}\text { Karşılaştırılmalı } \\
\text { Analiz }\end{array}$ & $1(1.8)$ & & \\
\hline $\begin{array}{c}\text { İçerik ve Betimsel } \\
\text { Analiz, Betimsel } \\
\text { İstatistik }\end{array}$ & $1(1.8)$ & & \\
\hline Faktör Analizi & $1(1.8)$ & & \\
\hline $\begin{array}{c}\text { Durum Odaklı ve } \\
\text { Karşılaştırılmalı } \\
\text { Durum Analizi }\end{array}$ & $1(1.8)$ & & \\
\hline $\begin{array}{c}\text { Tümdengelim } \\
\text { Analizi }\end{array}$ & $1(1.8)$ & $1(1.8)$ & $1(1.8)$ \\
\hline Meta-Sentez & & & $1(1.8)$ \\
\hline
\end{tabular}

Turkish Studies - Education, 15(4) 


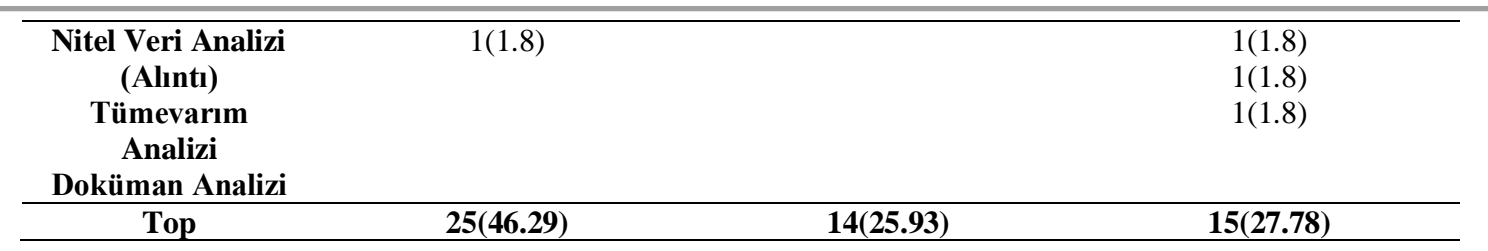

Tablo 7'de araştırmalar analiz çeşitlerine göre incelendiğinde; tüm çalışmalar arasından doktora tez çalışmalarındaki verilerin analizinde en çok 10 (\%18.5) betimsel analiz kullanıldığı görülmektedir. Yüksek lisans tezlerinde ise $5(\% 9.3)$ betimsel analiz ve $5(\% 9.3)$ içerik analizi tercih edilmiştir. Makalelerde ise 7 (\%12.9) içerik analizi tercih edildiği görülmektedir. Genel olarak incelendiğinde ise analiz yöntemi olarak betimsel analizin (\%33.3) ve içerik analizin $15(\% 27,78)$ kullanıldığı görülmüştür.

\section{Sonuç, Tartışma ve Öneriler}

Bu çalışmada 2010 y1lından 2019 yılına kadar 'ders imecesi" ya da "lesson study" anahtar kelimeleri ile doktora tezleri, yüksek lisans tezleri ve TR Dizinde indekslenen makaleler taranmıştır. Yapılan araştırmalarda doktora tezlerinin yüksek lisans tezlerinden daha fazla olduğu görülmektedir. Ders imecesi, bir mesleki gelişim modeli olup, önemi son yıllarda artmıştır (Gökkurt-Özdemir, 2020). Öğretmenlerin ve öğretmen adaylarının problem yaşadığı durumların çözümü için gerçek sınıf ortamlarında uygulamalar yapmaları önem taşımaktadır (Darling-Hammond \& Baratz-Snowden. 2005; Magnussan vd. 1999). Bu kapsamda Türkiye'de öğretmen yetiştiren kurumlarda öğretmen adaylarının ve aktif olan öğretmenlerin gelişimlerine yönelik bu mesleki gelişim modelinin kullanılması doktora yapan araştırmacıların dikkatini çekmiştir. Bu alandaki araştırmaların uzun bir süreç ve kapsamlı veri toplama sürecini gerektirmesi, incelenen çalışmalarda doktora tezlerinin sayısının fazla olmasının sebebi olarak gösterilebilir. TR-Dizin indeksli taranan makaleler incelendiğinde de bu modelin kullanıldığı çalışmalara rastlanmıştır. Bu araştırmada makalelerin tarandığ $\mathrm{Bu}$ kapsamda ders imecesi üzerinde alan taraması yapacak araştırmacıların, uluslararası indekslerde taranan makaleleri inceleyip, ders imecesinin uluslararası kapsamda hangi ülkelerin bu modeli çalıştıklarını ortaya koyarak Türkiye'deki durum ile karşılaştırmaları önerilmektedir.

Ders imecesi üzerine yapılan çalışmaların yıl dağı̆lımı incelendiğinde, her y1l nerdeyse bu alanda çalışma yapıldığı ve özellikle son yıllarda daha fazla çalışıldığı görülmektedir. Bu durum, Türkiye'de son yıllarda araştırmacıların bu modeli sıklıkla kullanmaya başladıklarını ve bu modele önem verdiklerini göstermektedir. Araştırmaların yürütüldüğü örneklem grubu incelendiğinde, araştırmacıların çoğunun öğretmenlerle çalıştıkları belirlenmiştir. Çoğu araştırmanın öğretmenlerle yürütülmesi, ders imecesinin öğretmenlik mesleği ile doğrudan ilişkili olduğunu göstermektedir. Öğretmenlerin branşları karşılaştıııldığında, araştırmada matematik öğretmenleri ve matematik öğretmeni adaylarının daha çok tercih edildiği görülmüştür. Bunun nedeni olarak ders imecesinin, ilk kez Japonya'da matematik öğretiminin geliştirilmesinde uygulanmış olması gösterilebilir. Oysa alanyazında bu modelin diğer alanlarda birçok kademede kullanıldığ 1 dikkat çekmektedir (Isoda, Stephens, Miyakawa, \& Ohara, 2007). Bu açılamaya dayalı olarak, diğer branşlarda da bu modelin kullanılmasına ilişkin çalışmaların arttırılmasına ihtiyaç vardır. $\mathrm{Bu}$ araştırmada fen bilgisi öğretmenleri ile yapılan araştırmalara rastlanamaması dikkat çekici sonuçlardan biridir. Oysa eğitim sistemi incelendiğinde, sistemde aktif olarak görev yapan öğretmenlerin mesleki gelişimlerinin var olan geleneksel yöntemler kapsamında tam olarak desteklenemediği ve bunu sağlamada yeni yaklaşımlara, modellere gereksinim duyulduğu vurgulanmaktadır (Küçükahmet, 1993). Bu nedenle, Türkiye'de geleneksel mesleki gelişim hizmetlerinin yaklaşımlar ve modeller açısından güncelleştirilmesi derslerin etkili olması açısından gerekli görülmektedir (Kandemir, 2018). Ders imecesi, bu noktada kullanılabilecek etkili modellerden biri olup, öğretmenlere olumlu mesleki gelişimler sağlayan yöntemlerden biridir (Akerson vd., 2017; Dubin, 2010; Groth, 2005; Meyer, 
2005; Saltzman, 2008). Bu doğrultuda, ders imecesi modelinin bütün branşlarda kullanılmas1 gerektiği söylenebilir. Özellikle küçük yaşlarda öğrenme güçlüğü olan ilkokul öğrencilerinin derslerini yürüten sınıf öğretmenlerinin (Fırat \& Erdem, 2020) ve kavram yanılgılarının fazla olduğu fen bilgisi (Adıgüzel, Şimşir, Çubukluöz, \& Gökkurt-Özdemir, 2018) derslerini yürüten fen bilgisi öğretmenlerinin mesleki gelişimlerinin arttırılmasında bu modelin kullanılmasına yönelik araştırmaların yapılması gerektiği önerilmektedir. Bunun yanında ortaokul öğrencilerinin matematiksel düşünme becerisi ve matematik dersine yönelik tutumu düşük olan araştırmalar (Erdem, Fırat \& Gürbüz, 2019; Erdem \& Soylu, 2017) göz önüne alındığında bu modelin her kademede kullanılmasının yararlı olacağı düşünülmektedir.

Araştırma deseni olarak incelendiğinde, çoğunlukla durum çalışmasının tercih edildiği görülmektedir. Ders imecesi öğretmen gelişim modeli olduğu için eylem araştırması yönteminin kullanıldığı çalışmaların arttırılması önerilmektedir. Çünkü eylem araştırmasında, süreç odaklı çalış1ır, uygulama yapılır, sorunun çözümüne yönelik veri toplanır, sorunla ilgili gelişme ve değişmeler uygulama yapılırken gözlemlenir. Ayrıntılı ve derinlemesine incelemeler ve gözlemler yapılır (Yıldırım \& Şimşek, 2013: 334-336). Eylem araştırması, uygulayıcıların karşılaş̧ıkları bir problemi ortadan kaldırmak veya var olan durumu daha iyi hale getirmek için kullanılan bir yöntemdir (Mills, 2003). Bu bakımdan, öğretmenlerin ya da öğretmen adaylarının mesleki gelişimlerinde karşılaştıkları sorunların giderilmesine yönelik çalışmaların arttırılmasının nitelikli bir öğretim sürecinin yürütülmesine, öğretmenlerin ve öğretmen adaylarının mesleki gelişimlerine katk1 sağlayacağı düşünülmektedir. Bu alanda doküman incelemesi yapacak araştırmacıların ders imecesi modelinde kullandıkları veri toplama araçlarını tema olarak incelemeleri önerilmektedir.

Araştırmalarda kullanılan yaklaşım incelendiğinde, en çok nitel yaklaşım tercih edilmiştir. $\mathrm{Bu}$ sonucun ortaya çıkmasının sebebi olarak ders imecesinde planlanmanın uzun olup, uygulamanın zaman alması gösterilebilir. Analiz yöntemi olarak da daha çok betimsel ve içerik analizinin tercih edildiği görülmektedir. Genel olarak araştırmaların içeriği özetlendiğinde, ders imecesinin öğretmenlerin profesyonel gelişimleri için ideal bir hizmet-içi eğitim yöntemi olarak kabul edildiği görülmektedir. Benzer şekilde Godfrey ve diğerleri (2019), bu modelin öğrencilerin öğrenme çıktılarına ilişkin değişiklikleri tespit etmede etkili olduğunu ve gelecekte kullanılması gerektiğini vurgulamaktadır. Türkiye gibi bu mesleki gelişim modelinin etkili bir şekilde uygulanabilmesi için bu alandaki çalışmaların tüm branşlarda görev yapan öğretmenler ve hizmet öncesinde öğrenim gören öğretmen adaylarıyla yapılmasının gerekli olduğu düşünülmektedir.

\section{Kaynakça}

Adıgüzel, T., Şimşir, F., Çubukluöz, Ö., \& Gökkurt Özdemir, B. (2018). Türkiye'de matematik ve fen eğitiminde kavram yanılgılarıyla ilgili yapılan yüksek lisans ve doktora tezleri: tematik inceleme. Bayburt Üniversitesi Eğitim Fakültesi Dergisi, 13(25), 57-92. https://doi.org/10.17680/erciyesakademia.291891

Akerson, V. L., Pongsanon, K., Rogers, M. A. P., Carter, I., \& Galindo, E. (2017). Exploring the use of lesson study to develop elementary preservice teachers' pedagogical content knowledge for teaching nature of science. International Journal of Science and Mathematics Education, 15(2), 293-312. https://doi.org/10.1007/s10763-015-9690-x

Aktürk, D. (2019). Matematik öğretmenlerinin ders imecesi kapsamında geliş̧tirdikleri stem etkinliklerine yönelik görüşlerinin incelenmesi [Yayımlanmamış yüksek lisans tezi]. Eskişehir Osmangazi Üniversitesi Eğitim Bilimleri Enstitüsü.

Armstrong, A. (2011). Lesson study puts a collaborative lens on student learning. Learning Forward, 14(4), 1-8. 
Baki, M. (2012). Sinıf öğretmeni adaylarının matematiği öğretme bilgilerinin gelişsiminin incelenmesi: Bir ders imecesi (lesson study) çalışması [Yayımlanmamış doktora tezi]. Karadeniz Teknik Üniversitesi Eğitim Bilimleri Enstitüsü.

Baki, M. \& Arslan, S. (2015). Ders imecesinin sınıf ögretmeni adaylarının matematik dersini planlama bilgilerine etkisinin incelenmesi. Türk Bilgisayar ve Matematik Eğitimi Dergisi, 6(2), 209-229. https://doi.org/10.16949/turcomat.02379

Bayram, İ. \& Bıkmaz, F. (2019). Ders imecesi modeli ve modelin öğretmen mesleki gelişimine katkısı üzerine bir inceleme. Ankara Üniversitesi Eğitim Bilimleri Fakültesi Dergisi, 52(2), 577-610. https://doi.org/10.30964/auebfd.473958

Boran, E. \& Tarım, K. (2016). Ortaokul matematik öğretmenlerinin ders imecesi hakkındaki görüşleri. Türk Bilgisayar ve Matematik Eğitimi Dergisi, 7(1), 259-273. https://doi.org/10.16949/turcomat.22182

Borko, H. (2004). Professional development and teacher learning: Mapping the terrain. Educational Researcher, 33(8), 3-15. https://doi.org/10.3102/0013189X033008003

Bozkurt, E. \& Yetkin-Özdemir, İ. E. (2018). Mesleki gelişimde işbirliğine dayalı bir yaklaşım: ders araştırmas1. Kastamonu Eğitim Dergisi, $26(1), \quad$ 109-116. https://dx.doi.org/10.24106/kefdergi.375675

Bütün, M. (2012). İlköğretim matematik öğretmeni adaylarının uygulanan zenginleştirilmiş program sürecinde matematiği ögretme bilgilerinin gelişimi [Yayımlanmamış doktora tezi]. Karadeniz Teknik Üniversitesi Eğitim Bilimleri Enstitüsü.

Chokshi, S. \& Fernandez, C. (2004). Challenges to importing Japanese lesson study: Concerns, misconceptions, and nuances, Phi Delta Kappan, 85(7), 520-525. https://dx.doi.org/10.1177/003172170408500710

Cumhur, F. (2016). Matematik öğretmeni adaylarının soru sorma davranışlarının gelişsiminin incelenmesi: bir ders imecesi çalışması. [Yayımlanmamış doktora tezi]. Karadeniz Teknik Üniversitesi Eğitim Bilimleri Enstitüsü.

Darling-Hammond, L. \& Baratz-Snowden, J. (2005). A good teacher in every classroom: preparing the highly qualified teachers our children deserve. John Wiley \& Sons.

Doig, B. \& Groves, S. (2011). Japanese lesson study: Teacher professional development through communities of inquiry. Mathematics Teacher Education and Development, 13(1), 77-93.

Dubin, J. (2010). American teachers embrace the Japanese art of lesson study. The Education Digest, 75(6), 23-29.

Eraslan, A. (2008). Japanese lesson study: Can it work in Turkey? Education and Science, 33(149), 62-67.

Erbilgin, E. (2013). Sınıf öğretmeni adaylarının ders araştırması hakkındaki görüşleri. Dicle Üniversitesi Ziya Gökalp Eğitim Fakültesi Dergisi, 21, 69-83. https://doi.org/10.14582/duzgef.519

Erdem, E., Firat, T., \& Gürbüz, R. (2019). Improving mathematical reasoning and mathematics attitude of disadvantaged children in rural regions. Journal of Computer and Education Research, 7(14), 673-697. https://dx.doi.org/10.18009/jcer.628742

Erdem, E., \& Soylu, Y. (2017). Age-and gender-related change in mathematical reasoning abilit and some educational suggestions. Journal of Education and Practice, 8(7), 116- 127. 
Fernandez, C. \& Yoshida, M. (2004). Lesson study: A case of a Japanese approach to improving instruction through school-based teacher development. Lawrence Erlbaum.

Fernandez, C., Yoshida, M., Chokshi, S., \& Cannon, J. (2001). An overview of lesson study, 1-36.

Firat, T. \& Erdem, E. (2020). Matematik öğrenmede güçlük yaşayan ilkokul öğrencilerinin 1. ve 4. sınıftaki süreçlerine ilişkin sınıf öğretmenlerinin görüşleri. Erzincan Üniversitesi Eğitim Fakültesi Dergisi, 22(1) , 66-86. https://dx.doi.org/10.17556/erziefd.504004

Godfrey, D., Seleznyov, S., Anders, J., Wollaston, N., \& Barrera-Pedemonte, F. (2019). A developmental evaluation approach to lesson study: exploring the impact of lesson study in London schools. Professional Development in Education, 45(2), 325-340.

Gómez,, E. S., Serván-Núñez, M. J., Trapero, N. P. \& Pérez-Gómez, A. I. (2019) Action research through lesson study for the reconstruction of teachers' practical knowledge. A review of research at Málaga University (Spain). Educational Action Research, 27(4), 527-542, https://dx.doi.org/10.1080/09650792.2019.1610020

Gökkurt-Özdemir， B. (2020). Matematik eğitiminde ders imecesi (lesson study) mesleki gelişim modeli. M. Ünlü (Ed.). Uygulama örnekleriyle matematik ögrretiminde yeni yaklaşımlar (s. 333-356). (1. Bask1). Pegem Akademi.

Groth, R. (2005). Improving teaching through lesson study. Mathematics Teacher Journal, 104(6), 446-451.

Güner, P. \& Akyüz, D. (2017). Ders imecesi mesleki gelişim modeli: öğretmen adaylarının fark etme becerilerinin incelenmesi. Illkögretim Online, 16(2), 428-452. https://dx.doi.org/ 10.17051/ilkonline.2017.304709

Isoda, M. (2007). Lesson study in teacher education programs: How do students

become teachers that implement lesson study? In M. Isoda, M. Stephens, Y. Ohara, \& T. Miyakawa (Eds.), Japanese lesson study in mathematics its impact, diversity and potential for educational improvement (pp. 176-179). World Scientific

Jhang, F. H. (2020) Teachers' attitudes towards lesson study, perceived competence, and involvement in lesson study: evidence from junior high school teachers. Professional Development in Education, 46(1), 82-96. https://doi.org/10.1080/19415257.2019.1585383

Karakuş, D. (2019). Ders imecesi yöntemiyle matematik ögretmeni adaylarının teknolojik pedagojik alan bilgilerinin gelişimlerinin incelenmesi: trigonometri örneği [Yayımlanmamış doktora tezi]. Atatürk Üniversitesi Eğitim Bilimleri Enstitüsü.

Kandemir, E. M. (2018). Sinıf öğretmenlerinin öğretim becerilerini geliştirmeye yönelik bir uygulama: Bir ders imecesi [Yayımlanmamış doktora tezi]. Pamukkale Üniversitesi Eğitim Bilimleri Enstitüsü.

Kaya, Ü. (2018). Lise matematik ögretmenlerinin ders imecesi modeline dayalı mesleki gelişim uygulamalarının değerlendirilmesi [Yayınlanmamış yüksek lisans tezi]. Cumhuriyet Üniversitesi Eğitim Bilimleri Enstitüsü.

Küçükahmet, L. (1993). Öğretmen yetiştirme (Programları ve uygulamaları). Gazi Üniversitesi

Lewis, C., Friedkin, S., Baker, E., \& Perry, R. (2011). Learning from the key tasks of lesson study. In O. Zaslavsky ve P. Sullivan (Eds.), Constructing knowledge for teaching secondary mathematics (pp. 161-176). Springer. 
Magnusson, S., Borko, H. \& Krajik, J. (1999). Nature, sources, and development of pedagogical content knowledge for science Teaching. In J. Gess-Newsome, \& N.G. Lederman (Eds.), Examining pedagogical content knowledge (pp. 95-132). Kluwer Academic Publishers.

Meyer, R. (2005). Lesson study: The effects on teachers and students in urban middle schools [Unpublished doctoral dissertation]. Baylor University.

Mills, G. E. (2003). Action research: A guide for the teacher researcher. (2nd Ed.). Merrill Prentice Hall.

Murata, A., Alston, A., \& Hart, L. (2011). Introduction: Conceptual overview of lesson study lesson study research and practice in mathematics education. L. Hart, A. Alston, \& A. Murata içinde, Lesson Study Research and Practice in Mathematics Education (pp. 1-12). Springer Netherlands.

Özbek, K. (2019). Ortaokul matematik öğretmenlerinin açılar konusunda kullandıkları öğretim yöntem ve tekniklerdeki gelişimleri ile ders imecesine yönelik görüşleri [Yayımlanmamış yüksek lisans tezi]. Ağrı İbrahim Çeçen Üniversitesi Fen Bilimleri Enstitüsü.

Özaltun-Çelik, A. \& Bukova-Güzel, E. (2016). Bir matematik öğretmenin ders imecesi boyunca öğrencilerin düşüncelerini ortaya çıkaracak soru sorma yaklaşımları. Türk Bilgisayar ve Matematik Eğitimi Dergisi, 7(2), 365-392. https://doi.org/10.16949/turcomat.67541

Saltzman, L. (2008). Integrating japanese lesson study in math curriculum: A case study. [Unpublished Master Thesis]. University of Alaska, Anchorage.

Sato, M. (2006). Gakko no chosen [Challenges of schools]. Shogakkan.

Stigler, J. \& Hiebert, J. (1999). The Teaching Gap: Best ideas from the world's teachers for improving education in the classroom. The Free Press.

Stigler, J. W. \& Hiebert, J. (2016). Lesson study, improvement, and the importing of cultural routines. ZDM, 48(4), 581-587. https://doi.org/10.1007/s11858-016-0787-7

Takahashi, A. \& Yoshida, M. (2004). Ideas for establishing lesson-study communities. Teaching Children Mathematics, 10(9), 436-443.

Verhoef, N.C., Coenders, F., Pieters, J.M., Smaalen, D.V., \& Tall, D.O. (2015). Professional development through lesson study: Teaching the derivative using GeoGebra. Professional Development in Education, 41(1), 109-126. https://dx.doi.org/10.1080/19415257.2014.886285

Yıldırım, A. \& Şimşek, H. (2013). Sosyal bilimlerde nitel araştırma yöntemleri (9.baskı). Seçkin Yayıncilık.

Yılmaz, N. (2019). Öğretmen adaylarının istatistiği öğretme bilgilerinin ögrretmenlik uygulaması temelli ders araştırmalar bağlamında incelenmesi [Yayımlanmamış doktora tezi]. Hacettepe Üniversitesi Eğitim Bilimleri Enstitüsü.

Yoshida, M. (2005). An overview of lesson study. In P. Wang-Iverson ve M. Yoshida (Eds.), Building our understanding of lesson study (pp. 3-14). Research for Better Schools.

Yurdakul, R. (2019). Matematik ögrretmenlerinin hizmet içi eğitimlerinde ders imecesi modelinin uygulama sürecini kolaylaştırmaya yönelik bir web sitesinin tasarlanması ve değerlendirilmesi [Yayımlanmamış yüksek lisans tezi]. Sivas Cumhuriyet Üniversitesi Eğitim Bilimleri Enstitüsü. 
Ek-1 İncelenen çalışmalar

1 TÜRKIYE, ABD, JAPONYA, INGILTERE VE AVUSTRALYA'DA FEN VE FIZIIK ÖĞRETMENLERINE YÖNELIK MESLEKI GELIŞiM PROGRAMLARININ KARŞILAŞTIRILMASI.

ORTAÖĞRETIM MATEMATIK ÖĞRETMENLERINININ PEDAGOJIK ALAN VE PEDAGOJIK BILGILERINDEKİ GELIȘiMIN, MODELLEME YAKLASSIMINA GÖRE TASARLANMIȘ BİR MESLEKİ GELIȘIM VE EĞITIM ETKİNLIĞİ SÜRECINDE INCELENMESI

3 SINIF ÖĞRETMENI ADAYLARININ MATEMATIĞİ ÖĞRETME BILGILERININ GELISTIMININ INNCELENMESİ: BIIR DERS İMECESI (LESSON STUDY) ÇALIȘMASI

4 DERS IMECESININ MATEMATIK ÖĞRETMENLERININ PROBLEM CÖZME ORTAMLARINDA ÖĞRENCILERININ ÜSTBILISSLERINII HAREKETE GEÇIRMEYE YÖNELIK DAVRANIŞLARINA ETKİSI

PIYANO DERSINDE KULLANILAN ÖĞRENME STRATEJILERININ ÇEŞITLİ DEĞİŞKENLER AÇISINDAN INCELENMESI

YAZAR

YILI

DÜRDANE 2010

BAYRAM

ARZU

AYDOĞAN

YENMEZ

MÜJGAN BAKİ

2012

AVNI YILDIZ

2013

ÖZLEM

KILINÇER

2013

SERAP

AKBABA DAĞ ÖĞRETMENI ADAYLARININ KESIR ÖĞRETIM BILGILERININ GELIŞTIRILMESINE YÖNELIKK BİR UYGULAMA

DERS ARAŞTIRMASI MODELİ BAĞLAMINDA ORTAOKUL MATEMATIKK ÖĞRETMENLERININ ÖĞRETIM FAALIYETLERINE YÖNELIK GRUP TEMELLİ ÖZDÜZENLEMELERININ INCELENMESI

MATEMATIK ÖĞRETMENI ADAYLARIYLA YÜRÜTÜLEN DERS IMMECESINDE DIŞ UZMANLARIN PAYLAŞIM IÇERIKLERİ VE ROLLERI

DERS ARAŞTIRMASI MODELİ BAĞLAMINDA ORTAOKUL MATEMATIK ÖĞRETMENLERININ ÖĞRETIM FAALIYETLERINE YÖNELIK GRUP TEMELLİ ÖZDÜZENLEMELERININ İNCELENMESI

MATEMATIK ÖĞRETMENI ADAYLARININ SORU SORMA DAVRANIȘLARININ GELISSIMININ İNCELENMESİ: BİR DERS İMECESİ ÇALIŞMASI
DERS IMECESI ÇALIŞMALARIYLA SINIF ÖĞRETMENLERININN PROBLEM ÇÖZMEYE DAYALI MATEMATIĞİ ÖĞRETME BİLGILERININ GELIȘiMININ İNCELENMESI

TECHNOLOGICAL PEDAGOGICAL CONTENT KNOWLEDGE (TPACK) DEVELOPMENT OF PRESERVICE MIDDLE SCHOOL MATHEMATICS TEACHERS IN STATISTICS TEACHING: A $\begin{array}{lll}\text { MICROTEACHING LESSON } & \text { STUDY }\end{array}$

ÖĞRETMENLERIN MESLEKİ GELISSIMLERINDE DERS ARAŞTIRMASI MODELINE YÖNELIK ÖĞRETMEN GÖRÜŞLERİ
ERHAN

BOZKURT

2015

OBEN

KANBOLAT

ERHAN

2015

BOZKURT

FATMA

CUMHUR

2016

EMINE GÖZEL 2016

GAMZE KURT

2016

SEMA

2016 
14 ORTAOKUL MATEMATİK ÖĞRETMENLERINİN MATEMATIĞİ ÖĞRETME BİLGILERININ GELIŞIM SÜRECININ INNCELENMESI: DERS İMECESİ MODELİ

GÜLSAH

ÖZDEMIR

BAKİ

MIKRO ÖĞRETIM DERS İMECESİ YÖNTEMIYLE MATEMATIK ÖĞRETMENI ADAYLARININ TEKNOLOJIK PEDAGOJIK ALAN BILGILERININ GELIŞSIMLERININ İNCELENMESI: GEOMETRIK CISIMLER ÖRNEĞİ

$\begin{array}{lrrr}\text { INVESTIGATING } & \text { PRESERVICE MIDDLE } & \text { SCHOOL } \\ \text { MATHEMATICS TEACHERS' NOTICING OF } & \text { STUDENTS' }\end{array}$ MATHEMATICAL THINKING IN THE CONTEXT OF LESSON STUDY

DERS ARAŞTIRMA MODELININ, ÖĞRETMENLERIN PROFESYONEL GELISSTIMLERI VE ÖZ-YETERLIK ALGILARI İLE ÖĞRENCILERIN ÖZ-DÜZENLEME BECERILERİ ÜZERINDEKI DEĞISSIMIN İNCELENMESI

(8)

PRACTICING LESSON STUDY WITH EFL TEACHERS: A SOCIAL CONSTRUCTIVIST PERSPECTIVE FOR EFL TEACHER PROFESSIONAL DEVELOPMENT

RUHŞEN

ALDEMIR

ZÜHAL

YILMAZ

DOĞAN

FERHAN

SINIF ÖĞRETMENLERININ ÖĞRETIM BECERILERINI GELISTTIRMEYE YÖNELIK BIR UYGULAMA: DERS İMECESI KANDEMIR

DERS IMECESI: INGILIZZCE HAZIRLIK PROGRAMI ÖĞRETMENLERININ LIDERLIĞİNDE BIR MESLEKİ GELISSIM UYGULAMASI

ILKNUR

BİR ORTAOKUL MATEMATIKK ÖĞRETMENININ DÖRTGENLER KONUSUNDAKİ SÖYLEMLERININ DEĞIŞIMININ INCELENMESİ

SEVGİ

ARIKAN

DERYA

DERS İMECESİ YÖNTEMIYLE MATEMATIK ÖĞRETMENI ADAYLARININ TEKNOLOJIK PEDAGOJIK ALAN BILGILERININ GELIŞSIMLERININ INNCELENMESI:

KARAKUŞ TRIGONOMETRİ ÖRNEĞII

ÖĞRETMEN ADAYLARININ ISTATISTIIĞİ ÖĞRETME NADIDE BILGILERININ ÖĞRETMENLIK UYGULAMASI TEMELLİ DERS YILMAZ ARAŞTIRMALARI BAĞLAMINDA İNCELENMESİ

AN EXAMINATION OF THE IMPACT OF AN ONLINE PROFESSIONAL DEVELOPMENT PROGRAM ON LANGUAGE TEACHERS' COGNITION AND TEACHING PRACTICES

BEHİCE

CEYDA

SONGÜL

ÖĞRETMEN ADAYLARI AÇISINDAN DERS ARAŞTIRMASI MODELININ MESLEKİ GELIŞIM KAPSAMINDA İNCELENMESI

AHMET

MATEMATIK ÖĞRETMENLERININ MESLEKİ GELIŞIMLERİ: ÖĞRENCI DÜŞÜNCESI BİLGISINIIN ÖĞRETIME YANSIMASI

AYTUĞ

ÖZALTUN

AYŞEGÜL META-SENTEZ ÇALIŞMASI SERBEST

ORTAOKUL MATEMATIK ÖĞRETMENLERININ DÖNÜŞÜM

2017

PINAR GÜNER

2017

ESIN MERAL 2018

SARI 2019

2019

2019

SEVDE ÖZBAY 2015 GEOMETRISINDE ALAN ÖĞRETIMI BILGILERININ INNCELENMESİ 


\begin{tabular}{|c|c|c|c|}
\hline 29 & $\begin{array}{l}\text { ORTAOKULLARDA OKUMA } \quad \text { BECERİLERİ } \\
\text { UYGULAMA ALANLARI: KAYSERİ İLİ ÖRNEĞİ }\end{array}$ & $\begin{array}{l}\text { HASAN } \\
\text { HÜSEYIN } \\
\text { MEYDAN }\end{array}$ & 2016 \\
\hline 30 & 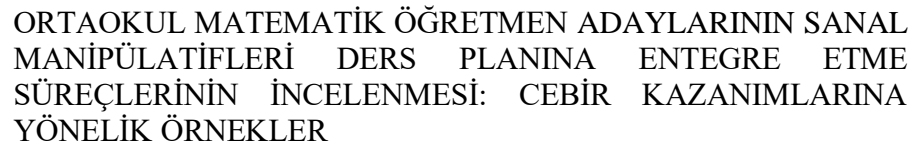 & $\begin{array}{l}\text { DİLAN TEMEL } \\
\text { DOĞAN }\end{array}$ & 2017 \\
\hline 31 & $\begin{array}{l}\text { ORTAOKUL MATEMATIK ÖĞRETMENLERINININ ÖZEL ALAN } \\
\text { YETERLILIK ALGILARININ INCELENMESİ: BIR } \\
\text { ARAŞTIRMASI MODELI }\end{array}$ & ELIFF BORAN & 2017 \\
\hline 32 & $\begin{array}{l}\text { DERS ARAŞTIRMASIYLA MATEMATIK ÖĞRETMENLERİNIN } \\
\text { YARATICI DRAMA YÖNTEMINI KULLANARAK MATEMATIĞI } \\
\text { ÖĞRETME BİLGILERININ GELIŞIMININ İNCELENMESİ }\end{array}$ & $\begin{array}{l}\text { GAMZE } \\
\text { BATIBAY }\end{array}$ & 2018 \\
\hline 33 & $\begin{array}{l}\text { LİSE MATEMATIK ÖĞRETMENLERINININ DERS İMECESİ } \\
\text { MODELINE DAYALI MESLEKİ GELIŞIM UYGULAMALARININ } \\
\text { DEĞERLENDİILMESI }\end{array}$ & ÜMİT KAYA & 2018 \\
\hline 34 & $\begin{array}{l}\text { İLKÖĞRETIM MATEMATIK ÖĞRETMEN ADAYLARININ } 5 . \\
\text { SINIF KESIRLER KONUSUNDA DERSE HAZIRLIK } \\
\text { SÜREÇLERININ LESSON STUDY (DERS İMECESI) } \\
\text { KAPSAMINDA INCELENMESİ }\end{array}$ & HİLAL KÜKEY & 2018 \\
\hline 35 & 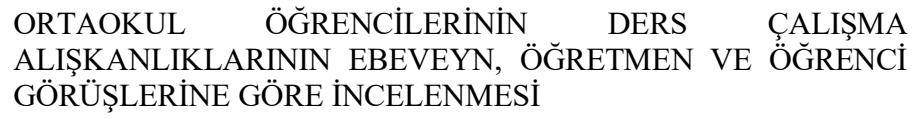 & $\begin{array}{l}\text { MERVENUR } \\
\text { OLTULU }\end{array}$ & 2019 \\
\hline 36 & $\begin{array}{l}\text { SOSYAL BILGİLER ÖĞRETMEN ADAYLARININ MESLEK } \\
\text { BİLGISI YETERLIKKLERINIIN GELIŞTIRILMESINDE DERS } \\
\text { İMECESİ UYGULAMASI }\end{array}$ & $\begin{array}{l}\text { TOLGAHAN } \\
\text { AYANTAŞ }\end{array}$ & 2019 \\
\hline 37 & $\begin{array}{l}\text { MATEMATIK ÖĞRETMENLERINİN DERS İMECESİ } \\
\text { KAPSAMINDA GELIŞTIRRDIKLERİ STEM ETKİNLIKKLERİNE } \\
\text { YÖNELIK GÖRÜŞLERINININ İNCELENMESİ }\end{array}$ & $\begin{array}{l}\text { DUDU NUR } \\
\text { AKTÜRK }\end{array}$ & 2019 \\
\hline 38 & $\begin{array}{lrrrr}\text { MATEMATIK } & \text { ÖĞRETMENLERININ } & \text { HIZMET } & \text { İÇI } \\
\text { EĞITIMLERINDE } & \text { DERS İMECESI } & \text { MODELININ } & \text { UYGULAMA } \\
\text { SÜRECINI } & \text { KOLAYLAŞTIRMAYA } & \text { YÖNELIK } & \text { BİR } & \text { WEB } \\
\text { SITESININ TASARLANMASI VE DEĞERLENDIRILMESİ }\end{array}$ & $\begin{array}{l}\text { RAMAZAN } \\
\text { YURDAKUL }\end{array}$ & 2019 \\
\hline 39 & 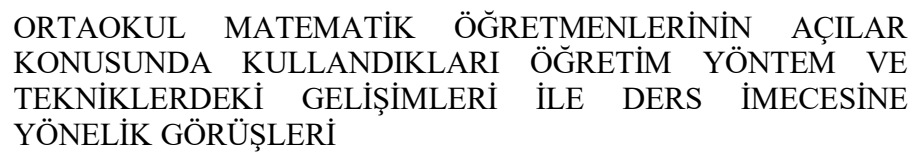 & $\begin{array}{l}\text { KÜBRA NUR } \\
\text { ÖZBEK }\end{array}$ & 2019 \\
\hline 40 & $\begin{array}{l}\text { PROFESSIONAL DEVELOPMENT OF JAPANESE SCIENCE AND } \\
\text { PHYSICS TEACHERS AND JAPANESE APPROACH IN } \\
\text { PROFESSIONAL DEVELOPMENT: "LESSON STUDY" }\end{array}$ & $\begin{array}{l}\text { DÜRDANE } \\
\text { BAYRAM } \\
\text { JACOBS }\end{array}$ & 2012 \\
\hline 41 & $\begin{array}{l}\text { SINIF ÖĞRETMENİ ADAYLARININ DERS ARAŞTIRMASI } \\
\text { HAKKINDAKİ GÖRÜŞLERİ }\end{array}$ & $\begin{array}{l}\text { EVRİM } \\
\text { ERBİLGIN }\end{array}$ & 2013 \\
\hline 42 & $\begin{array}{l}\text { EVALUATION OF THE LESSON STUDY MODEL IN TEACHING } \\
\text { PRACTICE COURSE: PROBLEMS AND SOLUTIONS }\end{array}$ & MESUT BÜTÜN & 2015 \\
\hline 43 & $\begin{array}{l}\text { DERS İMECESININ SINIF ÖĞRETMENI ADAYLARININ } \\
\text { MATEMATIK DERSINI PLANLAMA BILGILERINE ETKISININ } \\
\text { INCELENMESI }\end{array}$ & $\begin{array}{l}\text { MÜJGAN BAKİ } \\
\text { VE } \\
\text { SELAHATTIN } \\
\text { ARSLAN }\end{array}$ & 2015 \\
\hline
\end{tabular}




\begin{tabular}{|c|c|c|c|}
\hline 44 & $\begin{array}{l}\text { ‘'DERS ARAŞTIRMASI' UYGULAMASININ MATEMATIK } \\
\text { ÖĞRETMENLERININ MESLEKİ GELIŞIMLERINE VE ÖĞRENME } \\
\text { SÜRECININ GELIŞTİRMESINE ETKİİ }\end{array}$ & $\begin{array}{l}\text { REMZİ } \\
\text { KINCAL, } \\
\text { DİLEK } \\
\text { BEYPINAR }\end{array}$ & 2015 \\
\hline 45 & $\begin{array}{l}\text { ORTAOKUL MATEMATİK ÖĞRETMENLERİNIN DERS İMECESİ } \\
\text { HAKKINDAKİ GÖRÜŞLERİ }\end{array}$ & $\begin{array}{l}\text { ELIF BORAN, } \\
\text { KAMURAN } \\
\text { TARIM }\end{array}$ & 2016 \\
\hline 46 & $\begin{array}{l}\text { BİR MATEMATIK ÖĞRETMENIN DERS IMECESİ BOYUNCA } \\
\text { ÖGRENCILERIN DÜŞÜNCELERINI ORTAYA ÇIKARACAK } \\
\text { SORU SORMA YAKLAŞIMLARI }\end{array}$ & $\begin{array}{l}\text { AYTUĞ } \\
\text { ÖZALTUN } \\
\text { ÇELIK, ESRA } \\
\text { BUKOVA } \\
\text { GÜZEL }\end{array}$ & 2016 \\
\hline 47 & $\begin{array}{l}\text { DERS IMECESİ MESLEKİ GELIŞIM MODELİ: ÖĞRETMEN } \\
\text { ADAYLARININ FARK ETME BECERİLERININ İNCELENMESİ }\end{array}$ & $\begin{array}{l}\text { PINAR GÜNER, } \\
\text { DİDEM } \\
\text { AKYÜZ, }\end{array}$ & 2017 \\
\hline 48 & $\begin{array}{l}\text { ÖĞRETMEN ADAYLARININ DERS İMECESİ (LESSON STUDY) } \\
\text { KAPSAMINDA MATEMATIKSEL FARK ETME NITELIKLLERI }\end{array}$ & $\begin{array}{l}\text { PINAR GÜNER, } \\
\text { DİDEM AKYÜZ }\end{array}$ & 2017 \\
\hline 49 & $\begin{array}{l}\text { THE APPLICATION OF LESSON STUDY IN TEACHING } \\
\text { ENGLISH AS A FOREIGN LANGUAGE }\end{array}$ & $\begin{array}{l}\text { ABDULLAH } \\
\text { COŞKUN }\end{array}$ & 2017 \\
\hline 50 & $\begin{array}{l}\text { MATEMATIK } \quad \text { ÖĞRETMENLERINİN } \quad \text { DERS } \\
\text { KAPSAMINDA KÖKLC̈ İFADELİ } \\
\text { OLUŞTURDUKLARI DERS PLANI }\end{array}$ & $\begin{array}{l}\text { AYTUĞ } \\
\text { ÖZALTUN } \\
\text { ÇELIK, ESRA } \\
\text { BUKOVA } \\
\text { GÜZEL }\end{array}$ & 2017 \\
\hline 51 & $\begin{array}{l}\text { BİLIM SANAT MERKEZİ MATEMATIK ÖĞRETMENLERINIIN } \\
\text { KURDUKLARI GEOMETRİ İNŞA PROBLEMLERINE BİLIŞSEL } \\
\text { SEVIYE DÜZEYLERİ AÇISINDAN } \\
\text { ÇALIŞMALARININ ETKİSİ }\end{array}$ & $\begin{array}{l}\text { AVNI YILDIZ, } \\
\text { SERDAL } \\
\text { BALTACI }\end{array}$ & 2017 \\
\hline 52 & $\begin{array}{l}\text { ÖĞRENCILERİN MATEMATIKSEL DÜŞÜNMELERINE } \\
\text { YÖNELIK ÖGRETMENLERIN FARKINDALIK DÜZEYLERININ } \\
\text { İNCELENMESI: DERS İMECESİ MODELİ }\end{array}$ & $\begin{array}{l}\text { GÜLŞAH } \\
\text { ÖZDEMIR } \\
\text { BAKİ, AHMET } \\
\text { IŞIK }\end{array}$ & 2018 \\
\hline 53 & $\begin{array}{l}\text { EXPLORING THE LESSON STUDY EXPERIENCE OF EFL } \\
\text { INSTRUCTORS AT HIGHER EDUCATION: A PILOT STUDY }\end{array}$ & $\begin{array}{l}\text { İLKNUR } \\
\text { BAYRAM, } \\
\text { FATMA } \\
\text { BIKMAZ }\end{array}$ & 2018 \\
\hline 54 & $\begin{array}{l}\text { HOW DO PRESERVICE MATHEMATICS TEACHERS USE } \\
\text { VIRTUAL MANIPULATIVES TO TEACH ALGEBRA THROUGH } \\
\text { LESSON STUDY? }\end{array}$ & $\begin{array}{l}\text { DİLAN TEMEL } \\
\text { DOĞAN, } \\
\text { MERİÇ } \\
\text { ÖZGELDİ }\end{array}$ & 2018 \\
\hline
\end{tabular}

